American J. of Engineering and Applied Sciences 4 (1): 175-178, 2011

ISSN 1941-7020

(C) 2010 Science Publications

\title{
Computation of Irregular Boundary Area by Lacunary Interpolation Technique
}

\author{
Jamal Muhamad Amen \\ Department of Surveying, Sulaimani Technical Institute, Sulaimani, Iraq
}

\begin{abstract}
Problem statement: Rising up land value and a rapid extension in large town in the world, this in addition to appearance a new technique in applied mathematics especially in interpolation felid during last period encourage engineers and surveyor to search for a new mathematical formula for calculating area of a land. Approach: In this study, $(0,2)$ lacunary interpolation technique used to derive a new equation for calculation of a land area. Results: The results show that this new technique is better than the used formulas before, such as trapezoidal and Simpson's rule. Conclusion: The obtained formula can be use by engineer's and surveyor for calculating area of a land confidently and to acceptable accuracy.
\end{abstract}

Key words: Lacunary interpolation, cubic spline function, irregular boundary area, engineering surveying, calculating area, trapezoidal rule, Lacunary Cubic (LC), lacunary polynomial, irregular shape, instrumental method, geometric shapes

\section{INTRODUCTION}

In general, the shapes of any closed boundary area are divide into two types, the first one is regular shape which normally surrounded by straight lines or curves. Computation of area of such type is easy and can be done either by using existing formulas for computing regular geometric shapes such as square, rectangle and circle. or through dividing land area into triangles, then calculating the area of each triangle, sum of all triangles area give total required area.

The second type of existing area is that type which its boundary has irregular shape. A number of methods can be applied to compute the area of such types. A among these are instrumental method to calculate area in which a planimeter is used, (Shih, 1995), this in addition to other methods which was mentioned recently in some surveying text, (Kavanagh, 2008).

Trapezoidal rule is the prime rule for calculating such type of a land area; here the assumption is the boundary must be straight lines (first degree polynomial, Fig. 1). This rule can be use always irrespective the total number of offsets is even or odd and intervals are equal or unequal.

The way of taking data in field is selecting a base line then measuring offsets length from base line toward the outside boundary. A more accurate result value for area between a straight base line and irregular boundary may be obtained by taking offsets at regular intervals and Appling Simpson's one -third rule to that portion lying between an odd number offsets, (Kavanagh, 2008). Simpson's one- third rule which assumes that the curve through each successive point is portion of a parabola (second degree polynomial, Fig. 2) this rule has been used since a long time. The total area by Simpson's rule is equal to one-third the spacing between offsets, multiplied by the sum of the two extreme offsets, four times of the even offsets and twice the sum of the remaining odd offsets, (Kavanagh, 2008) and (Ahmad, 1983). Simpson 3/8 rule was mention in some text also, (Burden and Faires, 2004) and (Cheney and Kincaid, 2007), (Fig. 3).

Simpson's one third rules were extended for unequal intervals by (Easa, 1993). Ahmad (1983).presented a method that employed different polynomial functions using salient boundary points

A smooth approximating boundary (Fig. 4) for area computation using a cubic spline was employed by Chen and Lin and discussed by (Ahmad, 1983).

Easa (1993) has developed method of calculating irregular boundary area by using a cubic Hermite concept for deriving formulas for computing area directly instead of solving a system of linear equation to estimate the spline parameters first and then taking integration of the spline functions to find the area.

Both cubic spline and cubic Hermite was used before to treat the problem of sharp connections between the segments of the function. This study uses a new technique which is $(0,2)$ Lacunary interpolation by cubic spline for computing irregular boundary area and obtain a new formula (Fig. 5), \{(0,2) Lacunary interpolation means having information about the function itself and its second derivatives at all nodes in all segments to understand the subject of lacunary interpolation by spline see (Faraj and Karim, 2010). 


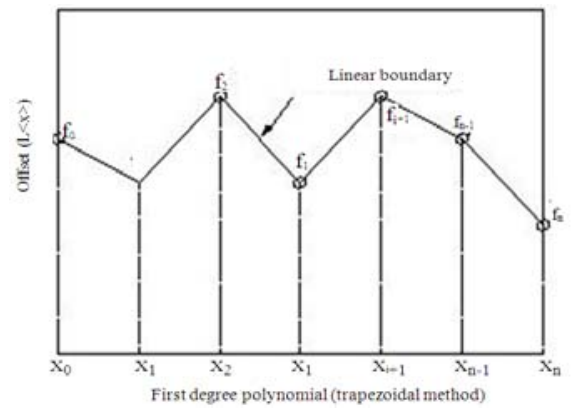

Fig. 1: First degree polynomial (trapezoidal method)

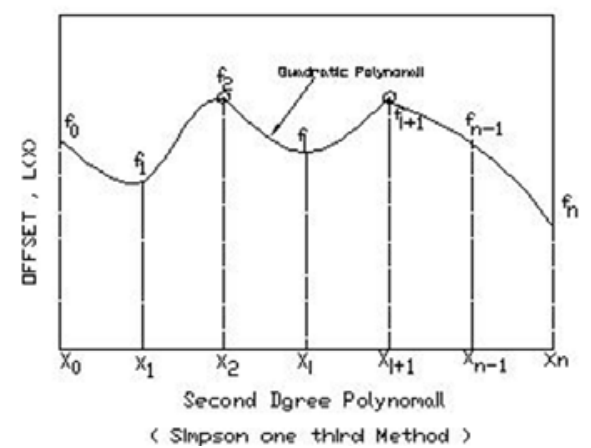

Fig. 2: Second degree polynomial (simpson one third method)

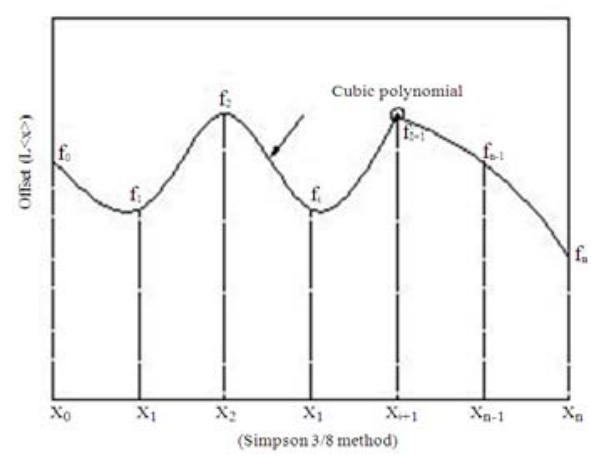

Fig. 3: Simpson 3/8 method

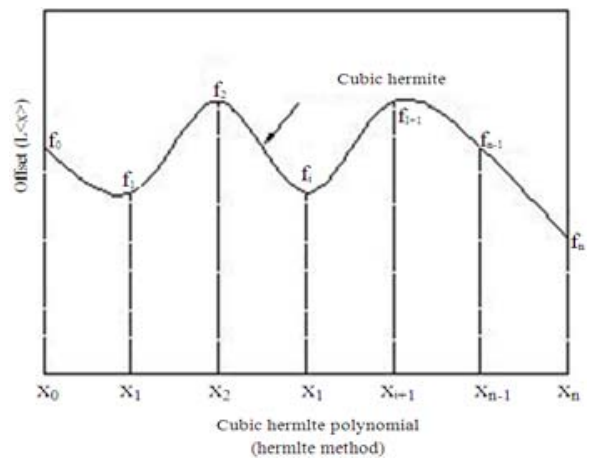

Fig. 4: Cubic hermite polynomial (hermitec method)

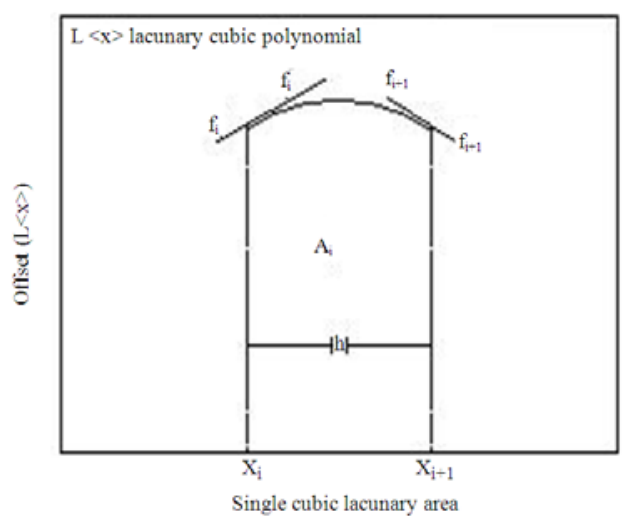

Fig. 5: Single cubic lacunary area

\section{MATERIALS AND METHODS}

Cubic lacunary polynomial: Suppose that $\mathrm{a}=$ $\mathrm{x}_{0}<\mathrm{x}_{1}<\mathrm{x}_{2}<\ldots . .<\mathrm{x}_{\mathrm{n}}=\mathrm{b}$ and $\mathrm{x}_{\mathrm{i}+1}=\mathrm{x}_{\mathrm{i}}+\mathrm{h}, \mathrm{i}=0,1,0, \ldots, \mathrm{n}-$ $1, \mathrm{~h}=\frac{\mathrm{b}-\mathrm{a}}{\mathrm{n}}$.

A cubic lacunary polynomial for this interval $\left(\mathrm{x}_{\mathrm{i}}\right.$, $\mathrm{x}_{\mathrm{i}+1}$ ) is a third degree polynomial passing through the two points $\left(\mathrm{x}_{\mathrm{i}}, \mathrm{f}_{\mathrm{i}}\right)$ and $\left(\mathrm{x}_{\mathrm{i}+1}, \mathrm{f}_{\mathrm{i}+1}\right)$ satisfying the second derivatives at two points $\mathrm{f}_{\mathrm{i}}^{\prime \prime}, \mathrm{f}_{\mathrm{i}+1}^{\prime \prime}$. The CL polynomial is:

$L_{i}(x)=a_{i}+b_{i}\left(x-x_{i}\right)+c_{i}\left(x-x_{i}\right)^{2}+d_{i}\left(x-x_{i}\right)^{3}$

Equation (1), has four unknowns $a_{i}, b_{i}, c_{i}$ and $d_{i}$, the values of these unknown can be obtained from four known conditions $\mathrm{f}_{\mathrm{i}}, \mathrm{f}_{\mathrm{i}+1}, \mathrm{f}_{\mathrm{i}}^{\prime \prime}$ and $\mathrm{f}_{\mathrm{i}+1}^{\prime \prime}$. For a case of equal interval, $\mathrm{h}=\mathrm{x}_{\mathrm{i}+1}-\mathrm{x}_{\mathrm{i}}$.

at $\mathrm{x}=\mathrm{X}_{\mathrm{i}} \rightarrow \mathrm{a}_{\mathrm{i}}=\mathrm{f}_{\mathrm{i}}$

at $\mathrm{x}=\mathrm{x}_{\mathrm{i}+1} \rightarrow \mathrm{a}_{\mathrm{i}}+\mathrm{b}_{\mathrm{i}} \mathrm{h}+\mathrm{c}_{\mathrm{i}} \mathrm{h}^{2}+\mathrm{d}_{\mathrm{i}} \mathrm{h}^{3}=\mathrm{f}_{\mathrm{i}+1}$

at $\mathrm{x}=\mathrm{x}_{\mathrm{i}} \rightarrow 2 \mathrm{C}_{\mathrm{i}}=\mathrm{f}^{\prime \prime}{ }_{\mathrm{i} \rightarrow \mathrm{C}_{i}}=\frac{\mathrm{f}^{\prime \prime}}{2}$

at $x=x_{i+1} f^{\prime \prime}+6 d h=f^{\prime \prime}{ }_{i+1} \rightarrow d_{i}=\frac{f_{i+1}^{\prime \prime}-f_{i}^{\prime \prime}}{6 h}$

Solving (2-5) we obtain:

$b_{i}=\frac{6\left(f_{i+1}-f_{i}\right)-h^{2}\left(2 f_{i}^{\prime \prime}+f_{i+1}^{\prime \prime}\right)}{6 h}$ 
Am. J. Engg. \& Applied Sci., 4 (1): 175-178, 2011

Table 1: Comparison of Areas by Exact and obtained Lacunary cubic Eq. 14

\begin{tabular}{|c|c|c|c|c|}
\hline$\underline{S}$ & Example & No. of Intervals & Exact area & Lacunary equation area \\
\hline 1 & $A=\int\left(\frac{1}{2} x^{3}-2 x^{2}+3 x+2\right) d x$ & 6 & 6 & 6.000 \\
\hline 2 & $A=\int\left(x^{3}+3 x^{2}+9 x+11\right) d x$ & 6 & 16.75 & 16.75 \\
\hline 3 & $A=\int\left(x^{3}+3 x^{2}+3 x+2\right) d x$ & 6 & 4.75 & 4.750 \\
\hline 4 & $A=\int_{0}^{0} \frac{1}{6}\left(x^{3}-6 x^{2}+9 x+6\right) d x$ & 6 & 4.125 & 4.125 \\
\hline
\end{tabular}

Table 2: Comparison of areas for different methods: Example 1

\begin{tabular}{llll}
\hline Methods & $\begin{array}{l}\text { Number of } \\
\text { intervals }\end{array}$ & $\begin{array}{l}\text { Resulted } \\
\text { Area }\end{array}$ & $\begin{array}{l}\text { Error } \\
(\%)\end{array}$ \\
\hline Exact & 24 equal & 1104.800 & - \\
Trapezoidal rule & 6 equal & 1127.840 & +2.1 \\
Simpson's one third rule & 6 equal & 1069.120 & -3.2 \\
Hermite method & 6 equal & 1093.910 & -1.0 \\
Lacunary method & 6 equal & 1093.787 & -1.0 \\
\hline
\end{tabular}

Table 3: Comparison of areas for different Methods Example 2

\begin{tabular}{llll}
\hline Methods & $\begin{array}{l}\text { Number of } \\
\text { intervals }\end{array}$ & $\begin{array}{l}\text { Resulted } \\
\text { Area }\end{array}$ & $\begin{array}{l}\text { Error } \\
\text { (\%) }\end{array}$ \\
\hline Exact & 24 equal & 33.88 & - \\
Trapezoidal Rule & 6 equal & 33.24 & -1.8 \\
Simpson's one third Rule & 6 equal & 32.72 & -3.4 \\
Hermite method & 6 equal & 33.27 & -1.8 \\
Lacunary Method & 6 equal & 33.265 & -1.8 \\
\hline
\end{tabular}

Equation 2, 4, 5 and 6 give the four unknowns.

\section{RESULTS AND DISCUSSION}

Single CL Area: The area under the single CL polynomial between $\mathrm{X}_{\mathrm{i}}$ and $\mathrm{X}_{\mathrm{i}+1}$ is obtained by integrating (1):

$$
\begin{aligned}
& A_{i}=\int_{x_{i}}^{x_{i+1}}\left(a_{i}+b_{i}\left(x-x_{i}\right)+c_{i}\left(x-x_{i}\right)^{2}+d_{i}\left(x-x_{i}\right)^{3}\right) d x \\
& A_{i}=a_{i h}+\frac{b_{i} h^{2}}{2}+\frac{c_{i} h^{3}}{3}+\frac{d_{i h}{ }^{4}}{4}
\end{aligned}
$$

Substituting values of $\mathrm{a}_{\mathrm{i}}, \mathrm{b}_{\mathrm{i}}, \mathrm{c}_{\mathrm{i}}$ and $\mathrm{d}_{\mathrm{i}}$ from Eq. 2, 4, 5 and 6 in (7) then integrating:

$$
A_{i}=\frac{h}{24}\left\{12\left(f_{i}+f_{i+1}\right)-\left(f^{\prime \prime}+f^{\prime \prime}{ }_{i+1}\right) h^{2}\right\}
$$

The total area from $x_{0}$ to $x_{n}$, where $A$ is the sum of the single CL areas given by (9) then:

$$
A=\sum_{i=0}^{n-1} A_{i}
$$

Substituting for $A_{i}$ and canceling similar term:

$$
\begin{aligned}
A_{i}= & \frac{h}{12}\left\{12\left(f_{n}+f_{0}\right)+24 \sum_{i=1}^{n-1} f_{i}-h^{2}\left(f_{n}^{\prime \prime}+f_{0}^{\prime \prime}\right)-\right. \\
& \left.2 h^{2} \sum_{i=1}^{n-1} f_{i}^{\prime \prime}\right\}
\end{aligned}
$$

Which is the generalized CL formula for computing the area of an irregular region the unknown second derivatives, $\mathrm{f}_{0}^{\prime \prime}-\mathrm{f}_{\mathrm{n}}^{\prime \prime}$, are estimated numerically, has been derived using the known offsets. Employing Taylor's theorem $\mathrm{f}_{\mathrm{i}}^{\prime \prime}$ has been derived using numerical differentiation:

$f_{i}^{\prime \prime}=\frac{\left(f_{i+1}-2 f_{i}+f_{i-1}\right)}{h^{2}}, i=1,2, \ldots, n-1$,

Similarly, the second derivatives, $\mathrm{f}_{0}^{\prime \prime}$ and $\mathrm{f}_{\mathrm{n}}^{\prime \prime}$ are:

$\mathrm{f}_{0}^{\prime \prime}=\frac{\left(\mathrm{f}_{0}-2 \mathrm{f}_{1}+\mathrm{f}_{2}\right)}{\mathrm{h}^{2}}$

$f_{n}^{\prime \prime}=\frac{\left(f_{n}-2 f_{n-1}+f_{n-2}\right)}{(-1)}$

Then substituting (11), (12) and (13) in (10) and obtain the CL formula:

$$
\begin{aligned}
A_{i}= & \frac{h}{24}\left\{12\left(f_{n}+f_{0}\right)+28 \sum_{i=1}^{n-1} f_{i}-2 \sum_{i=1}^{n-1}\left(f_{i+1}+f_{i-1}\right)-\right. \\
& \left.\left(f_{2}-2 f_{1}+f_{0}+f_{n-2}-2 f_{n-1}+f_{n}\right)\right\}
\end{aligned}
$$

Examples and verification: Obtained Lacunary Cubic (LC) Eq. 14 was tested on some assumed cubic polynomial function; the results were tabulated in the following Table 1.

Equation 14 checked by testing it on the same data of Example 1 and Example 2 of the paper which was prepared by (Essa, 1993) and comparison made among some other different methods, the results tabulated in the following Table 2-5, Also the equation tested on the following tabulated date which was taken directly from the field, the data and results were tabulated as follow. 
Am. J. Engg. \& Applied Sci., 4 (1): 175-178, 2011

Table 4: List of field data

\begin{tabular}{ll}
\hline Distances, $\mathrm{m}$ & Offsets, (f), $\mathrm{m}$ \\
\hline 0 & 2.00 \\
2.5 & 2.70 \\
5 & 3.60 \\
7.5 & 4.40 \\
10 & 3.80 \\
12.5 & 4.35 \\
15 & 3.20 \\
\hline
\end{tabular}

Table 5: Comparison of areas for different methods filed data

\begin{tabular}{llll}
\hline Methods & $\begin{array}{l}\text { Number of } \\
\text { intervals }\end{array}$ & $\begin{array}{l}\text { Resulted } \\
\text { area }\end{array}$ & $\begin{array}{l}\text { Error } \\
(\%)\end{array}$ \\
\hline Exact & 6 equal & 53.99998 & - \\
Trapezoidal rule & 6 equal & 53.62500 & -0.70 \\
Simpson's one third rule & 6 equal & 54.83333 & +1.54 \\
Hermite method & 6 equal & 54.16667 & +0.30 \\
Lacunary method & 6 equal & 54.16667 & +0.30 \\
\hline
\end{tabular}

Equation for best curve fitting which pass above tabulated points:

$$
\begin{aligned}
y= & f(x)=1.961924+0.3512454 x-(2.814662 \mathrm{E} \\
& -x^{2}-(1.15574 \mathrm{E}-3) x^{3}
\end{aligned}
$$

\section{CONCLUSION}

In this study, I included that, the new formula which obtained in Eq. 14 give better results than trapezoidal and Simpson's one third rule. Both method lacunary technique and $\mathrm{CH}$ (Cubic Hermite) give the same results this means the new appearance mathematics technique can be test in applied mathematics field in future.

\section{REFERENCES}

Ahmad, F.A., 1983. Area computation using salient boundary points. J. Surv. Eng., 109: 54-63. DOI: 10.1061/(ASCE)0733-9453(1983)109:1(54)

Burden, R.L. and J.D. Faires, 2004. Numerical Analysis. 8th Edn., Brooks Cole, USA., ISBN-10: 0534392008, pp: 864.

Cheney, W. and D. Kincaid, 2007. Numerical Mathematics and Computing. 6th Edn., Brooks Cole, USA., ISBN-10: 9780495114758, pp: 784.

Easa, S.M., 1993. Smooth boundary approximation for directly computing irregular area. J. Surv. Eng., 119: $\quad 86-101 . \quad$ DOI: $10.1061 /(A S C E) 0733-$ 9453(1993)119:3(86)

Faraj, J.K.H. and R.G. Karim, 2010. Generalization of $(0,4)$ lacunary interpolation by quantic spline. J. Math. Stat., 6: 72-78. DOI: 10.3844/jmssp.2010.72.78

Kavanagh, B.F., 2008. Surveying: Principles and Applications. 8th Edition, Pearson Prentice Hall, USA., ISBN-10: 013236512X, pp: 791.

Shih, T.Y., 1995. Area computation by coordinates. J. Surv. $\quad$ Eng., 121 : 145-154. DOI: 10.1061/(ASCE)0733-9453(1995)121:4(145) 